\title{
RATE OF INCREASE IN WORKLOAD DETERMINES THE MOBILIZATION RATE BUT NOT THE DEGREE OF INCREASE IN ECG PARAMETERS
}

\author{
Kristina Poderienė, Alfonsas Buliuolis, Vilma Papievienė, Jonas Poderys \\ Lithuanian Sports University, Kaunas. Lithuania
}

\begin{abstract}
Background. The aim of this study was to compare the peculiarities of the dynamics of cardiovascular functional state indices during bicycle ergometry by applying the steep or slow increase in workload.

Methods. Twenty five males attending health promotion sport clubs took part in two cardiovascular testing procedures by performing graded exercise stress, i.e. increase in workload every $1 \mathrm{~min}$, and increase in workload every $6 \mathrm{~min}$, and they exercised till the inability to continue the task or unless distressing cardiovascular symptoms supervened; 12 lead ECG was recorded and analysed.

Results. The steep increase of registered cardiovascular parameters was observed at onset of exercising and the rate of was in dependence on the rate of the increase in workload. Registered maximal changes of heart rate, JT interval, and the ratio JT/RR as functional state indices at the moment of refusing to continue the graded exercise test were at the same level while applying the steep or slow increase in workload.

Conclusions. The rate of increase in workload determines the mobilization rate but not the degree of increase of ECG parameters. Maximal changes of heart rate, JT interval, and the ratio JT/RR as functional state indices at the moment of refusing to continue the graded exercise test were at the same level while applying the steep or slow increase in workload.
\end{abstract}

Keywords: cardiovascular system, graded exercise stress, functional state.

\section{INTRODUCTION}

$\mathrm{A}$ $t$ the onset of exercise a lot of body systems adapt to the variations of load. Consequently, a number of indices exist for the measurement of response of body functions to workload. In practice, the response to exercise can be evaluated by measuring the changes in the performance of one or another system (Cao et al., 2015; Giardini, Odendaal, Khambadkone, \& Derrick, 2011; Hettinga, Monden, van Meeteren, \& Daanen, 2014; Hughson \& Tschakovsky, 1999; Roberts, 2014; Vainoras, 2002).

There are a lot of studies presenting the dynamics of cardiovascular indices during graded exercise stress (Alihanoglu et al., 2015; Ceci et al., 2013; Olson et al., 2012; Shin, J. I. Park, S. K. Park, \& Barrett-Connor, 2014; Vainoras, 2002).
Concerning the problem of evaluation of the peculiarities in mobilization of body functioning during exercising, the two factors are important: first, the velocity of adaptation at onset of exercise, and second, to what extent the body function was mobilised.

The various protocols for increase in workload during the graded exercise stress could be used. The steep increase in workload induces the faster development of fatigue while the slow increase in workload allows slow adaptation to exercising and demonstration of the best results of muscular performance (Dawson et al., 2005; Munch et al., 2014; Poderys, Buliuolis, Poderytė, \& Sadzevičienè, 2005). The aim of this study was to compare the peculiarities in dynamics of cardiovascular 
functional state indices during bicycle ergometry by applying the steep or slow increase in workload.

\section{METHODS}

The participants of the study (males attending health promotion sport, $n=25$ ) had spent $20 \mathrm{~min}$ seated and after registration the base-line values of cardiovascular indices underwent a $50 \mathrm{~W}$ increase in workload, i.e. graded exercise test (bycicle ergometry) and they exercised till the inability to continue the task or unless distressing cardiovascular symptoms supervened. The subjects underwent a $50 \mathrm{~W}$ increase in workload every 60 seconds (60 revolutions/min). Two protocols for increase in workload were applied. First, increase in workload every $1 \mathrm{~min}$, and the second, increase in workload every 6 min.

A computerized ECG analysis system "Kaunas-load" was applied for 12 lead ECG recording and analysis. The changes in heart rate (HR), JT interval, and in the ratio of intervals JT/ RR were analysed. Standard ABP measurement was performed with pneumatic cuff by listening to "Korotkoff tones".

The significance of the difference between the values was evaluated by computing $t$ criterion; the paired $t$-test was used. The difference has been considered statistically significant at $p<.05$ (95 CI).

\section{RESULTS}

Working capacity. The task for the participants of this study was to continue exercising as much as they can, i.e. till the inability to continue it. Table 1 presents the data of working capacity while the two incremental protocols were used. All the participants of this study were able to continue the task, i.e. to perform the exercise up to $250 \mathrm{~W}$ (5 min), some of them were able to perform the exercise at the stage of $350 \mathrm{~W}$ (up to $7 \mathrm{~min}$ ) while the new stage of increased workload was 1 minute. While the new stage of increased workload was 6 minutes, all participants were able to perform the exercise up to $150 \mathrm{~W}$ (18 $\mathrm{min})$, some of them were able to perform it at the stage of $350 \mathrm{~W}$ (up to $32 \mathrm{~min}$ ).

Dynamics of cardiovascular indices. Figure 1 presents the dynamics of HR during the graded exercise test applying two protocols of the increase in workload. There were no significant differences $(p>.05)$ between the initial values before exercising. The steep increase in HR was observed at onset of exercising and the rate of was in dependence on the rate of increase in workload. There were no statistically significant differences $(p>.05)$ between maximal HR values registered at the end of the exercising $(176.7 \pm 3.9$ beats $/ \mathrm{min}$ while the increase in workload every $1 \mathrm{~min}$ was applied and $169.5 \pm 4.6$ beats $/ \mathrm{min}$ while the increase in workload every 6 min was applied).

Table 1. Working capacity while two different protocols for increase in workload was applied

\begin{tabular}{|c|c|c|c|c|c|c|c|c|c|}
\hline Indices & \multicolumn{9}{|c|}{ Increase in workload every $1 \mathrm{~min}$} \\
\hline Workload & $50 \mathrm{~W}$ & $100 \mathrm{~W}$ & $150 \mathrm{~W}$ & $200 \mathrm{~W}$ & $250 \mathrm{~W}$ & $300 \mathrm{~W}$ & $350 \mathrm{~W}$ & & \\
\hline Total duration of exercising & $1 \mathrm{~min}$ & $2 \min$ & $3 \min$ & $4 \min$ & $5 \min$ & $6 \min$ & $7 \min$ & & \\
\hline \multirow[t]{2}{*}{ Number of participants } & 25 & 25 & 25 & 25 & 25 & 16 & 4 & & \\
\hline & \multicolumn{9}{|c|}{ Increase in workload every $6 \mathrm{~min}$} \\
\hline Workload & \multicolumn{3}{|c|}{$50 \mathrm{~W}$} & \multicolumn{3}{|c|}{$100 \mathrm{~W}$} & \multicolumn{3}{|c|}{$150 \mathrm{~W}$} \\
\hline Total duration of exercising & $2 \min$ & $4 \min$ & $6 \mathrm{~min}$ & $8 \mathrm{~min}$ & $10 \mathrm{~min}$ & $12 \min$ & $14 \min$ & $16 \mathrm{~min}$ & $18 \mathrm{~min}$ \\
\hline Number of participants & 25 & 25 & 25 & 25 & 25 & 25 & 25 & 25 & 25 \\
\hline Workload & \multicolumn{3}{|c|}{$200 \mathrm{~W}$} & \multicolumn{3}{|c|}{$250 \mathrm{~W}$} & \multicolumn{3}{|c|}{$300 \mathrm{~W}$} \\
\hline Total duration of exercising & $20 \mathrm{~min}$ & $22 \mathrm{~min}$ & $24 \min$ & $26 \mathrm{~min}$ & $28 \mathrm{~min}$ & $30 \mathrm{~min}$ & $32 \mathrm{~min}$ & & \\
\hline Number of participants & 16 & 11 & 8 & 6 & 4 & 4 & 2 & & \\
\hline
\end{tabular}


Figure 2 presents the dynamics of JT interval of ECG during the graded exercise test applying two protocols of increase in workload. There were no significant differences $(p>.05)$ between durations of JT intervals registered before exercising. At onset of exercising and the rate of changes was in dependence on the rate increase in workload. There were no statistically significant differences $(p>.05)$ between the shortest JT interval values registered at the end of the exercising $(0.162 \pm 0.005$ $\mathrm{s}$ while the increase in workload every $1 \mathrm{~min}$ was applied and $0.164 \pm 0.004 \mathrm{~s}$ while the increase in workload every 6 min was applied).

Similar changes as a HR changes were find in comparison with the dynamics of the ratio of ECG intervals JT/RR during the graded exercise test applying two protocols of increase in workload. There were no statistically significant differences
Figure 1. HR dynamics during the graded exercise test applying two protocols of increase in workload

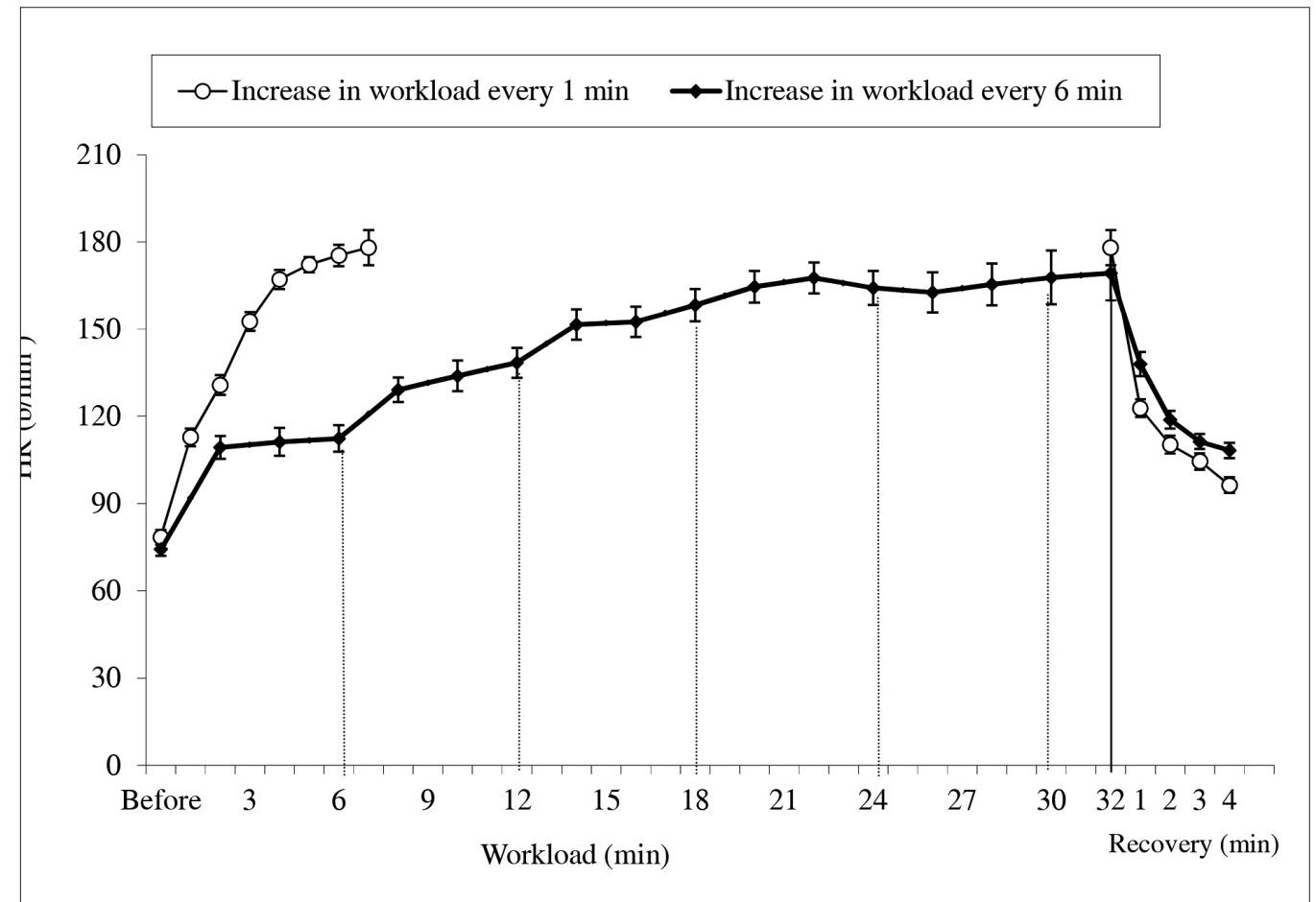

Figure 2. JT interval dynamics during the graded exercise test applying two protocols of increase in workload

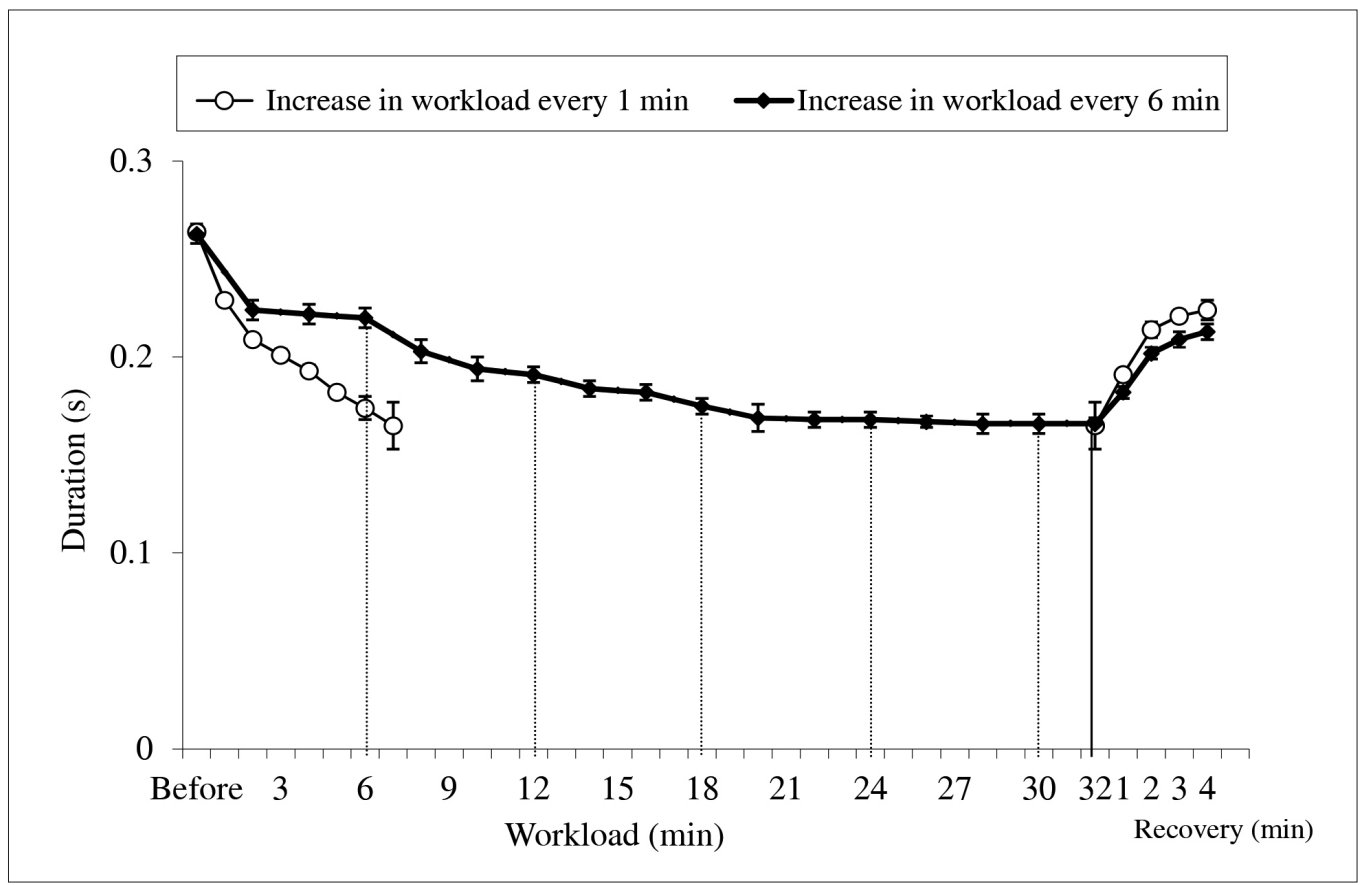




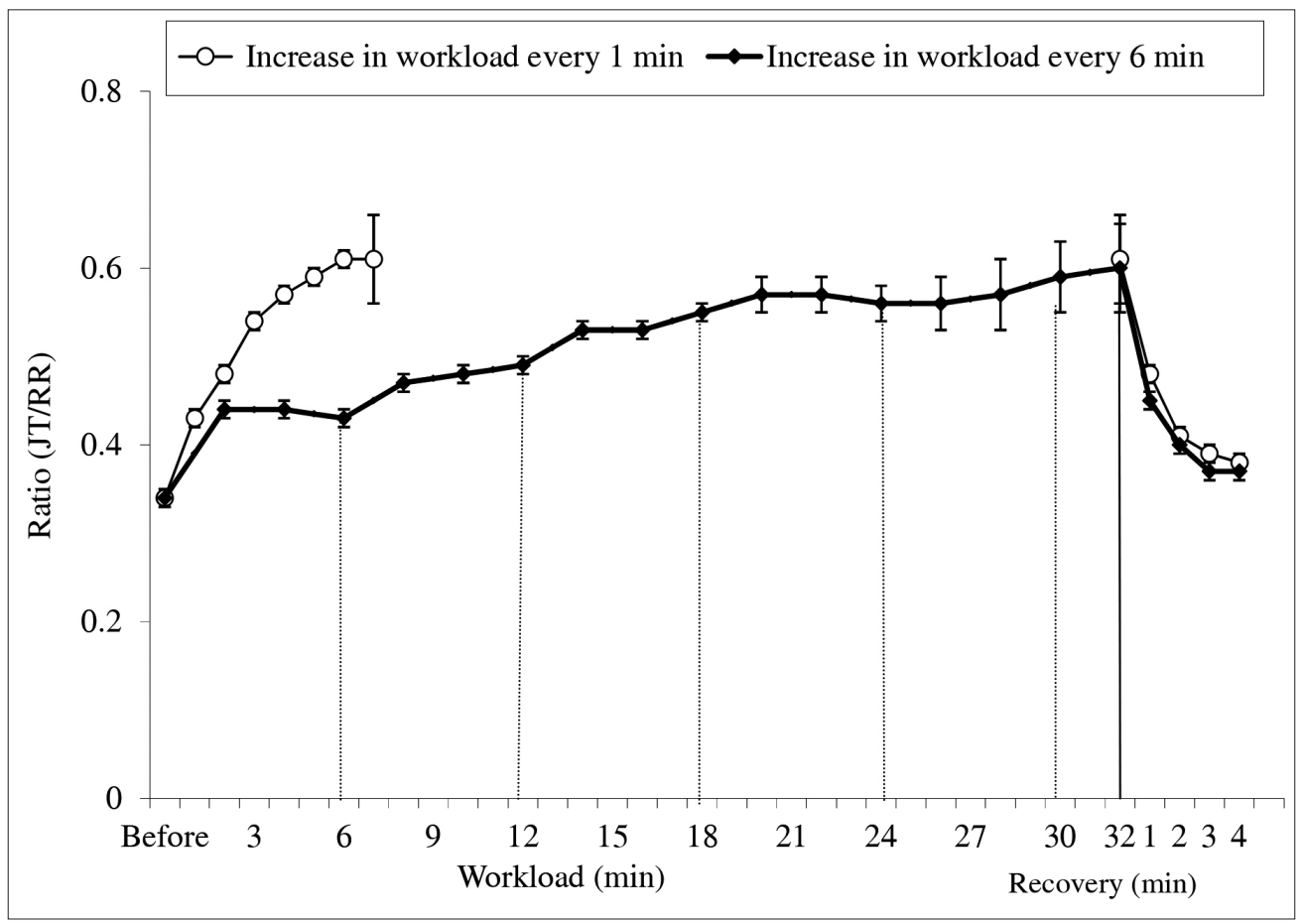

Figure 3. Dynamics of ratio of ECG intervals JT/RR during the graded exercise test applying two protocols of increase in workload

\begin{tabular}{|l|c|c|c|c|}
\hline \multirow{2}{*}{\multicolumn{1}{|c|}{ Indices }} & \multicolumn{2}{|c|}{ Before workload } & \multicolumn{2}{c|}{ At the end of workload } \\
\cline { 2 - 5 } & $\begin{array}{c}\text { Increase in } \\
\text { workload every } \\
\mathbf{1} \text { min }\end{array}$ & $\begin{array}{c}\text { Increase in } \\
\text { workload every } \\
\mathbf{6} \text { min }\end{array}$ & $\begin{array}{c}\text { Increase in } \\
\text { workload every } \\
\mathbf{1} \text { min }\end{array}$ & $\begin{array}{c}\text { Increase in } \\
\text { workload every } \\
\mathbf{6} \text { min }\end{array}$ \\
\hline HR (beats/min) & $78.5 \pm 2.5$ & $74.3 \pm 2.2$ & $176.7 \pm 3.9$ & $169.5 \pm 4.6$ \\
\hline JT interval (s) & $0.264 \pm 0.003$ & $0.263 \pm 0.005$ & $0.162 \pm 0.005$ & $0.164 \pm 0.004$ \\
\hline JT/RR & $0.342 \pm 0.01$ & $0.34 \pm 0.01$ & $0.610 \pm 0.01$ & $0.616 \pm 0.04$ \\
\hline Systolic ABP (mmHg) & $124.0 \pm 2.1$ & $126.2 \pm 2.1$ & $185.8 \pm 6.8$ & $204.2 \pm 6.3$ \\
\hline Diastolic ABP (mmHg) & $75.6 \pm 1.5$ & $77.6 \pm 1.3$ & $23.3 \pm 5.6$ & $29.2 \pm 6.7$ \\
\hline $\begin{array}{l}\text { Total peripheral resistance } \\
\text { (mmHg/l/min) }\end{array}$ & $16.8 \pm 1.3$ & $16.0 \pm 1.4$ & $3.8 \pm 0.7$ & $2.7 \pm 1.0$ \\
\hline
\end{tabular}

Table 2. Values of ECG indices registered during the graded exercise stress while two different protocols were applied

$(p>.05)$ between the JT/RR values registered at the end of the exercising $(0.610 \pm 0.01$ while the increase in workload every $1 \mathrm{~min}$ was applied and $0.616 \pm 0.04$ while the increase in workload every 6 min was applied).

In general, the dynamics of cardiovascular parameters while performing the graded exercise stress has the same tendency of stepwise changes with each new stage of workload. This tendency was strongly expressed during the first stages of workout and weakened when exercising became subjectively hard, i.e. during the last stages of workout. The values of cardiovascular indices registered at rest and at the moment of their maximal change, usually at the end of exercising, are presented in Table 2. As it was established during the analysis of figures presented in Table 2 , a statistically significant difference was found $(p<.05)$ while the values of systolic ABP at the end of exercising were compared. There were no significant differences observed between other registered ECG indices at the end of exercising.

\section{DISCUSSION}

Various indices for outlying cardiovascular response to exercising and physical exertion have been suggested; their applicability and value 
are widely discussed and analyzed in research literature (Boettger et al., 2010). Dynamics of HR during exercising is a commonly accepted measure of intensity of exercising and provides the clear understanding of the dynamics of functional state. HR is easily measurable index and various types of heart rate monitors have been widely used in sports for over 30 years (Achten \& Jeukendrup, 2003). Some authors consider the HR response measurement as a convenient non-invasive evaluation tool to monitor and analyze individual workouts (Dellal et al., 2012; Hettinga et al., 2014; Jeukendrup \& VanDiemen, 1998). Increases in the severity of exercise leads to increases in HR until it reaches its maximum, which is relatively constant in a particular person.

JT interval is not independent of the ventricular repolarisation pattern and can be used as an accurate means of estimating the duration of ventricular depolarisation (Banker, Dizon, \& Reiffel, 1997; Chiladakis et al., 2012) and its changes interrelate with the intensity of heart metabolism (Vainoras, 2002). In some studies it was shown that the change in the ratio of JR/RR intervals of ECG allows assessing the dynamics of mobilization of cardiovascular system during the exercise tests or workouts (Ežerskis, 2005; Poderys et al., 2005; Žumbakytè-Šermukšnienė, Kajenienė, Vainoras, Berškienè, \& Augutienè, 2010). The results obtained in this study confirm the same idea, i.e. the ratio of JT/RR can be useful for outlining to what extent the cardiovascular function was mobilised. As it was found during the incremental increase in workload (till the inability to continue the task), the ratio in JT/RR has varied very closely or even coincided with what was established by Boshkow (Бочков, 1986). According to Boshkow (Бочков, 1986), these biological constants can be expressed mathematically $(1 / \mathrm{e}=0.368$ and $1-1 / \mathrm{e}=$ 0.632). When performing dosed workloads (Roufier test - aerobic workout) and during 30-second all-out test in jumping (anaerobic workout), the changes in ratio of JT/RR were in dependence on the performance abilities (training experience) and functional state. This is evidence that the ratio of JT and RR intervals (JT/RR) of ECG provides the information concerning the dynamics of mobilization of cardiovascular system.

Changes of various cardiovascular indices during graded exercise stress could be useful for outlying the peculiarities of functioning and personal features of cardiovascular system (Alihanoglu et al., 2015; Ceci et al., 2013; Olson et al., 2012; Shin et al., 2014;Vainoras, 2002). The results obtained during this study showed that maximal changes of HR, JT interval, and the ratio of JT/RR as functional state indices at the moment of refusing to continue the graded exercise test were of the same level while applying the steep or slow increase in workload.

\section{CONCLUSION}

The rate of increase in workload determines the mobilization rate but not the degree of increase of ECG parameters.

\section{REFERENCES}

Achten, J., \& Jeukendrup, A. E. (2003). Heart rate monitoring: Applications and limitations. Sports Medicine, 33(7), 517-538.

Alihanoglu, Y. I., Yildiz, B. S., Kilic, I. D., Uludag, B., Demirci, E. E., Zungur, M., ... Kaftan, A. H. (2015). Impaired systolic blood pressure recovery and heart rate recovery after graded exercise in patients with metabolic syndrome. Medicine (Baltimore), 94(2), e428. doi: 10.1097/MD.0000000000000428

Banker, J., Dizon, J., \& Reiffel, J. (1997). Effects of the ventricular activation sequence on the JT interval. The American Journal of Cardiology, 79, 816-819.

Boettger, S., Puta, C., Yeragani, V. K., Donath, L., Müller, H. J., Gabriel, H. H., \& Bär, K. J. (2010). Heart rate variability, QT variability, and electrodermal activity during exercise. Medicine and Science in Sports and Exercise, 42(3), 443-448. doi: 10.1249/ MSS.0b013e3181b64db1

Cao, Y., Zhang, Y., Su, Y., Bai, J., Wang, W., \& Ge, J. (2015). Assessment of adaptive rate response provided by accelerometer, minute ventilation and dual sensor compared with normal sinus rhythm during exercise: A self-controlled study in chronotropically competent subjects. Chinese Medical Journal, 128(1), 25-31. doi: 10.4103/0366-6999.147798.

Ceci, R., Beltran Valls, M. R., Duranti, G., Dimauro, I., Quaranta, F., Pittaluga, M., ... Caporossi D. (2013). Oxidative stress responses to a graded maximal exercise test in older adults following explosive-type resistance training. Redox Biology, 2C, 65-72. doi: 10.1016/j. redox.2013.12.004. 
Chiladakis, J., Kalogeropoulos, A., Koutsogiannis, N., Zagkli, F., Vlassopoulou, N., Chouchoulis, K., ... Alexopoulos, D. (2012). Optimal QT/JT interval assessment in patients with complete bundle branch block. Annals of Noninvasive Electrocardiology: The Official Journal of the International Society for Holter and Noninvasive Electrocardiology, Inc. 17(3), 268276. doi: 10.1111/j.1542-474X.2012.00528.x

Dawson, E. A., Shave, R., George, K., Whyte, G., Ball, D., Gaze, D., \& Collinson, P. (2005). Cardiac drift during prolonged exercise with echocardiographic evidence of reduced diastolic function of the heart. European Journal of Applied Physiology, 94(3), 305-309.

Dellal, A., Owen, A., Wong, D. P., Krustrup, P., van Exsel, M., \& Mallo, J. (2012). Technical and physical demands of small vs. large sided games in relation to playing position in elite soccer. Human Movement Science, 31(4), 957-969. doi: 10.1016/j

Ežerskis, M. (2009). Didelio meistriškumo graikuromènu imtynininku širdies ir kranjagysliu sistemos funkciniu rodikliu kaita metiniame treniruotes cikle (Dynamics of cardiovascular functional indices of elite Greco-Roman wrestlers during annual training cycle) (Doctoral dissertation). Kaunas: LKKA.

Giardini, A., Odendaal, D., Khambadkone, S., \& Derrick, G. (2011). Physiologic decrease of ventilatory response to exercise in the second decade of life in healthy children. American Heart Journal, 161(6), 1214-1219. doi: 10.1016/j.ahj.2011.03.008

Hettinga, F. J., Monden, P. G., van Meeteren, N. L., \& Daanen, H. A. (2014). Cardiac acceleration at the onset of exercise: A potential parameter for monitoring progress during physical training in sports and rehabilitation. Sports Medicine, 44(5), 591-602. doi: 10.1007/s40279013-0141-y.

Hughson, R. L., \& Tschakovsky, M. E. (1993). Cardiovascular dynamics at the onset of exercise. Medicine and Science in Sports and Exercise, 31, 10051010.

Jeukendrup, A., \& VanDiemen, A. (1998). Heart rate monitoring during training and competition in cyclists. Journal of Sports Sciences, 16, 91-99.
Munch, G. D., Svendsen, J. H., Damsgaard, R., Secher, N. H., González-Alonso, J., \& Mortensen, S. P. (2014). Maximal heart rate does not limit cardiovascular capacity in healthy humans: Insight from right atrial pacing during maximal exercise. The Journal of Physiology, 592(2), 377-390. doi: 10.1113/ jphysiol.2013.262246

Olson, K. M., Augeri, A. L., Seip, R. L., Tsongalis, G. J., Thompson, P. D., \& Pescatello, L. S. (2012). Correlates of endothelial function and the peak systolic blood pressure response to a graded maximal exercise test. Atherosclerosis, 222(1), 202-207. doi: 10.1016/j. atherosclerosis.2012.01.027

Poderys, J., Buliuolis, A., Poderyte, K., \& Sadzevičienè, R. (2005). Mobilization of cardiovascular function during the constant-load and all-out exercise tests. Medicina (Kaunas), 41(12), 1048-1053.

Roberts, S. (2014). Fed or fasted? New considerations for exercise and glycemic response testing: Author's response re.: Assessment of the post-exercise glycemic response to food: Considering prior nutritional status. Nutrition, 30(1), 122-123. doi: 10.1016/j. nut.2013.07.022

Shin, S. Y., Park, J. I., Park, S. K., \& Barrett-Connor, E. (2014). Utility of graded exercise tolerance tests for prediction of cardiovascular mortality in old age: The Rancho Bernardo Study. International Journal of Cardiology, 181C, 323-327. doi: 10.1016/j. ijcard.2014.12.026

Vainoras, A. (2002). Functional model of human organism reaction to load evaluation of sportsmen training effect. Education. Physical Training. Sport, 44, 88-93.

Žumbakytė-Šermukšnienè, R., Kajenienè, A., Vainoras, A., Berškienė, K., \& Augutienè, V. (2010). Assessment of functional conditions of basketball and football players during the load by applying the model of integrated evaluation. Medicina (Kaunas), 46, 421-428.

Бочков, В. Г. (1986). Многовариантность регулирования в биологических системах и новые физиологические константы (Versatility of regulation in biological systems and new physiological constants) (Summary of doctoral dissertation). Kiev. 